\title{
Differences in subjective and objective respiratory parameters in patients with chronic obstructive pulmonary disease with and without pain
}

This article was published in the following Dove Press journal:

International Journal of COPD

25 February 2012

Number of times this article has been viewed

\section{Signe Berit Bentsen ${ }^{1,2}$ \\ Tone Rustøen ${ }^{3,4}$ \\ Christine Miaskowski ${ }^{5}$}

'Stord/Haugesund University College, Department of Health Education, Haugesund, Norway; ${ }^{2}$ Haugesund Hospital, Department of Research, Haugesund, Norway; ${ }^{3}$ Department of Research and Development, Division of Emergencies and Critical Care, Oslo University Hospital, Ullevål, Oslo, Norway; ${ }^{4}$ Lovisenberg Diaconal University College, Oslo, Norway; ${ }^{5}$ Department of Physiological Nursing, School of Nursing, University of California, San Francisco, California, USA
Correspondence: Signe Berit Bentsen Stord/Haugesund University College, Department of Health Education, Haugesund, Norway

Tel +475270 2737

Fax +475270 260

Email signe.bentsen@hsh.no
Background: Few studies have evaluated the associations between respiratory parameters and pain in chronic obstructive pulmonary disease (COPD). The purpose of this study is to evaluate the differences in respiratory parameters between COPD patients who did and did not have pain.

Methods: In this cross-sectional study respiratory parameters were measured by spirometry and the St Georges Respiratory Questionnaire. Patients responded to a single question that asked if they were generally bothered by pain.

Results: Of the 100 patients, $45 \%$ reported that they were generally bothered by pain. Patients who had pain reported a higher number of comorbidities $(P<0.001)$ and higher breathlessness scores $(P=0.003)$. Physical dimensions of breathlessness were significantly associated with pain $(P \leq 0.03)$. The results of logistic regression analysis determined that a higher number of comorbidities $(\mathrm{OR}=0.28 ; P=0.026)$ and higher breathlessness scores $(\mathrm{OR}=1.03 ; P=0.003)$ made significant unique contributions to the prediction of pain group membership.

Conclusions: Comorbidity and breathlessness were risk factors for pain and the physical dimensions of breathlessness were associated with pain.

Keywords: COPD, pain, comorbidity, lung function, breathlessness

\section{Introduction}

Of patients with advanced chronic obstructive pulmonary disease (COPD), approximately 94\% report breathlessness and $40 \%$ report pain. ${ }^{1}$ In the palliative phases of COPD, prevalence rates for breathlessness increase to $95 \%-98 \%$ and for pain to $68 \%-72 \%{ }^{2,3}$ While both of these symptoms are common in COPD, only six studies have investigated these two symptoms in the same patients. ${ }^{1-6}$

Pain has long been recognized as a symptom that includes a variety of sensations and multiple dimensions. ${ }^{7}$ Breathlessness is described as a subjective experience of breathing discomfort that consists of qualitatively distinct sensations that vary in intensity. ${ }^{8}$ Only recently, though, was the multidimensional model of pain applied to the symptom of breathlessness. ${ }^{9}$ In that paper, Lansing et al illustrated how breathlessness is a multidimensional construct, similar to pain, which consists of at least three separate and distinct qualities, namely "air hunger", "work", and "tightness". "Air hunger" is the perception of the urge to breath. This fundamental biological drive arises when pulmonary ventilation is insufficient. "Work" is perceived as being uncomfortable when the work of breathing is increased by high ventilation, by increasing resistance to inspiration, weakness of respiratory muscles, or shortened inspiratory muscle length. "Tightness" appears to be associated with bronchoconstriction. ${ }^{9,10}$ Taken together, in patients with COPD, bronchoconstriction, airflow limitations, decreased ventilation, and 
hyperinflation may give rise to the sensations of air hunger, increased work of breathing and tightness., ${ }^{9,10}$

Breathlessness and pain may share common neurophysiological pathways. ${ }^{9}$ Recent evidence suggests that the anterior insula is a critical structure involved in the perception of the emotional aspects of breathlessness and pain. Within this paradigm, pain is viewed as a part of the arousal/stress system that is characterized by increased sympathetic activation, which results in an increased respiratory rate. ${ }^{9}$ In a recent study of patients with fibromyalgia, ${ }^{11}$ patients who were taught slow breathing reported decreases in pain intensity. ${ }^{11}$ Of note, the use of slow breathing had a greater effect on moderate pain than on mild pain. ${ }^{11}$ This finding suggests that breathing rate influences pain intensity., ${ }^{9,11}$

While information on the relationship between pain intensity and breathlessness is increasing, little is known about the relationships between these two symptoms in patients with COPD. In one study that evaluated a number of respiratory parameters and pain in patients with $\mathrm{COPD},{ }^{5}$ increases in self-reported breathlessness were associated with increases in pain $(r=-0.22, P<0.05)$. In addition, decreases in oxygen saturation were associated with increased pain $(r=0.23$, $P<0.05) .{ }^{5}$ In a more recent study, ${ }^{6}$ while no associations were found between objective measures of lung function and pain intensity, increased breathlessness was associated with increased pain intensity $(r=0.26, P<0.01)$.

Given the paucity of research on the associations between pain and breathlessness in patients with COPD, the purposes of this study were to evaluate for differences in subjective (ie, breathlessness) and objective (ie, lung function) respiratory parameters between COPD patients who did and did not have pain, and to evaluate which subjective and objective respiratory variables provided unique contributions to explain the likelihood of being classified in the pain group at the time of enrollment into a pulmonary rehabilitation program.

\section{Methods}

\section{Design, sample, and data collection}

This cross-sectional study enrolled 136 patients with COPD who were recruited between August 2005 and August 2007 prior to enrollment in a pulmonary rehabilitation program. Patients were included if they were: $>35$ years of age; diagnosed with COPD by a pulmonary physician; reported symptoms of breathlessness, chronic cough, and sputum production; had a $\mathrm{FEV}_{1} / \mathrm{FVC}<70 \%$ and $\mathrm{FEV}_{1}<80 \%$ predicted; and were able to read and write Norwegian. The exclusion criteria for the study were using long-term oxygen treatment and unstable heart disease.
Patients were approached in the outpatient clinic and were given verbal and written information about the study. Patients who were willing to participate signed the informed consent and underwent spirometry. In addition, all patients were asked to complete a number of self-report questionnaires and to return them in a postage paid envelope. After 2 weeks, a reminder letter was sent to those who had not returned the questionnaires. The study was approved by the hospital unit, the Regional Committee for Medical Research Ethics, and the Norwegian Social Science Data Services.

\section{Instruments}

\section{Demographic characteristics}

Patients completed a demographic questionnaire that obtained information on age (continuous variable in years), sex (male, female), education (primary school, secondary school, and university), marital status (married/partnered, unmarried, widowed, divorced/separated), employment status (full or part time, not employed), smoking (current smoker, previous smoker, never smoked), comorbidities (yes, no), and other chronic medical conditions (myocardial infarction, angina, stroke, diabetes, cancer, osteoporosis, fibromyalgia, chronic pain, rheumatoid arthritis, osteoarthritis, ankylosing spondylitis, skeletal/muscle diseases, psychiatric diagnosis, gastrointestinal disease, asthma).

\section{Lung function}

Spirometry was performed with a Vitalograph Alpha spirometer (Vitalograph Alpha, Lenexa, KS), according to published guidelines. ${ }^{12}$ Forced expiratory volume in one second $\left(\mathrm{FEV}_{1}\right)$ and forced vital capacity $(\mathrm{FVC})$ were measured and the predicted values calculated according to a Norwegian reference population. ${ }^{13} \mathrm{FEV}_{1}(\mathrm{~L})$ and $\mathrm{FEV}_{1}$ as a percentage of the predicted value (predicted $\mathrm{FEV}_{1} \%$ ) were used as a measure of lung function.

\section{Disease severity}

Disease severity was classified using the Global Initiative for COPD (GOLD) criteria: mild, moderate, severe, and very severe COPD, defined as $\mathrm{FEV}_{1} / \mathrm{FVC}<0.7, \mathrm{FEV}_{1} \geq 80 \%$ predicted, $\mathrm{FEV}_{1} 50 \%-80 \%$ predicted, $\mathrm{FEV}_{1} 50 \%-30 \%$ predicted, or $\mathrm{FEV}_{1}<30 \%$ predicted, respectively. ${ }^{14}$

\section{Breathlessness}

Breathlessness was measured with the St George's Respiratory Questionnaire (SGRQ). ${ }^{15}$ SGRQ is a disease-specific questionnaire that measures health status for patients with pulmonary disease. The questionnaire consists of 76 items 
divided into three components: symptoms, activity, and impact. A sum is calculated for each component. Each of the component scores can range from 0 to 100 , with lower scores indicating better health status. ${ }^{16-18}$ The SGRQ has been translated into different languages and has satisfactory reliability and validity in COPD patients. ${ }^{19-21}$ As was done in previous studies, ${ }^{15,18}$ the symptom component score was used as the measure of breathlessness. The symptom component consists of eight items, including frequency and distress from breathlessness in terms of phlegm/sputum, shortness of breath, wheezing, and chest trouble. ${ }^{15,18}$ In addition, the following individual breathlessness items were evaluated: my cough hurts; my cough makes me tired; I get breathless when I bend over; my cough or breathing disturbs my sleep; and I get exhausted easily. Each item was scored using the 0 (wrong) versus 1 (right) format. The symptom component score, as well as the individual item scores, were used to evaluate differences in cough and breathlessness in COPD patients with and without pain.

\section{Pain}

Patients were categorized into the pain versus no pain groups based on their responses to the following question: "Are you generally bothered by pain?"

\section{Statistical analyses}

Data were analyzed using SPSS (v16.0; SPSS Inc, Chicago, IL). Descriptive statistics were used to evaluate demographic, clinical, respiratory, and pain variables. Chi-square and independent sample $t$-tests were used to evaluate for differences in demographic and clinical characteristics, and respiratory parameters between COPD patients who did and did not have pain. Multiple logistic regression analysis was done to evaluate the impact of specific respiratory parameters (ie, breathlessness and lung function) on pain status (ie, having or not having pain) after controlling for clinical characteristics (ie, number of comorbidities) that showed significant bivariates association with pain. Model fit was assessed using the Hosmer and Lemeshow test. A $P$-value of $<0.05$ was considered statistically significant.

\section{Results}

Of the 136 patients who met the inclusion criteria, 100 accepted the invitation to participate in this study (response rate of $74 \%)$. No differences were found in the age $(P=0.60)$ or sex distribution $(P=0.92)$ of the patients who did and did not participate in this study. Of the 100 COPD patients who participated in the study, $45 \%$ responded "yes" to the question "Are you generally bothered by pain?"

\section{Differences in demographic and clinical characteristics between COPD patients who did and did not have pain}

As shown in Table 1, no significant differences were found in any demographic characteristics between COPD patients who did and did not have pain. As shown in Table 2, compared to patients without pain, COPD patients with pain were more likely to report the presence of a comorbidity

Table I Differences in demographic characteristics between patients with chronic obstructive pulmonary disease who did $(\mathrm{N}=45)$ and did not $(\mathrm{N}=55)$ have pain

\begin{tabular}{|c|c|c|c|c|c|c|c|}
\hline \multirow[t]{2}{*}{ Demographics } & \multicolumn{3}{|c|}{ COPD patients with pain $(N=45)$} & \multicolumn{3}{|c|}{ COPD patients without pain $(N=55)$} & \multirow[t]{2}{*}{$P$-value } \\
\hline & Mean & SD & Range & Mean & SD & Range & \\
\hline \multirow[t]{2}{*}{ Age (years) } & 65.0 & 9.2 & $43-83$ & 67.9 & 7.3 & $50-80$ & 0.08 \\
\hline & $\underline{\mathbf{N}}$ & $\%$ & & $\underline{\mathbf{N}}$ & $\%$ & & \\
\hline Sex & & & & & & & 0.55 \\
\hline Male & 21 & 47 & & 30 & 55 & & \\
\hline Female & 24 & 53 & & 25 & 45 & & \\
\hline Education & & & & & & & 0.71 \\
\hline Primary school & 24 & 53 & & 25 & 46 & & \\
\hline Secondary school & 17 & 38 & & 22 & 41 & & \\
\hline University & 4 & 9 & & 7 & 13 & & \\
\hline Marital status & & & & & & & 0.91 \\
\hline Married/partners & 28 & 64 & & 37 & 68 & & \\
\hline Unmarried & 2 & 4 & & 2 & 4 & & \\
\hline Widow & 6 & 14 & & 8 & 15 & & \\
\hline Divorced/separated & 8 & 18 & & 7 & 13 & & \\
\hline Employment status & & & & & & & 0.36 \\
\hline Full or part time & 13 & 29 & & 11 & 20 & & \\
\hline Not employed & 32 & 71 & & 43 & 80 & & \\
\hline
\end{tabular}

Abbreviation: COPD, chronic obstructive pulmonary disease. 
Table 2 Differences in clinical characteristics between patients with COPD who did $(N=45)$ and did not $(N=55)$ have pain

\begin{tabular}{|c|c|c|c|c|c|c|c|}
\hline \multirow[t]{2}{*}{ Characteristics } & \multicolumn{3}{|c|}{ COPD patients with pain $(N=45)$} & \multicolumn{3}{|c|}{ COPD patients without pain $(\mathrm{N}=55)$} & \multirow[t]{2}{*}{$P$-value } \\
\hline & Mean & SD & Range & Mean & SD & Range & \\
\hline Number of comorbidities & 2.6 & 1.9 & $7-15$ & 1.0 & 0.87 & $0-15$ & $<0.001$ \\
\hline Pack years & 39.6 & 29.5 & $3-140$ & 33.4 & 20.3 & $0-100$ & 0.24 \\
\hline Lung function (FEV $\%$ predicted) & 47.8 & 15.8 & 19-79 & 44.5 & 14.3 & $16-79$ & 0.27 \\
\hline \multirow[t]{2}{*}{ Breathlessness (SGRQ) (0-100) } & 58.9 & 25.4 & $9.8-97.5$ & 42.4 & 27.7 & $0.0-93.9$ & 0.003 \\
\hline & $\mathbf{N}$ & $\%$ & & $\mathbf{N}$ & $\%$ & & \\
\hline Comorbidity & & & & & & & 0.016 \\
\hline Yes & 40 & 89 & & 36 & 67 & & \\
\hline No & 5 & 11 & & 18 & 33 & & \\
\hline Smoking & & & & & & & 0.24 \\
\hline Current smoker & 18 & 44 & & 13 & 27 & & \\
\hline Previous smoker & 23 & 56 & & 35 & 71 & & \\
\hline Never smoked & 0 & 0 & & 1 & 2 & & \\
\hline Disease severity & & & & & & & 0.09 \\
\hline Moderate & 24 & 53 & & 20 & 36 & & \\
\hline Severe & 14 & 31 & & 29 & 53 & & \\
\hline Very severe & 7 & 16 & & 6 & 11 & & \\
\hline
\end{tabular}

Abbreviations: COPD, chronic obstructive pulmonary disease; FEV , forced expiratory volume in I second; SGRQ, St George's Respiratory Questionnaire.

( $P=0.016)$; had a significantly higher number of comorbidities $(P<0.001)$; and reported a higher breathlessness score on SGRQ $(P=0.003)$. In terms of self-reported occurrence of chronic medical conditions (see Table 3 ), a higher percentage of COPD patients with pain reported chronic pain $(22 \%$; $P<0.001)$ and musculoskeletal diseases $(24 \% ; P=0.003)$ compared to those who did not have pain.

Table 3 Comparison of prevalence of various comorbid conditions between patients with COPD who did $(N=45)$ and did not $(\mathrm{N}=55)$ have pain

\begin{tabular}{|c|c|c|c|c|c|}
\hline \multirow[t]{2}{*}{ Conditions } & \multicolumn{2}{|c|}{$\begin{array}{l}\text { COPD } \\
\text { patients } \\
\text { with pain } \\
(\mathbf{N}=45)\end{array}$} & \multicolumn{2}{|c|}{$\begin{array}{l}\text { COPD } \\
\text { patients } \\
\text { without pain } \\
(\mathrm{N}=55)\end{array}$} & \multirow[t]{2}{*}{$P$-values } \\
\hline & $\mathbf{N}$ & $\%$ & $\mathbf{N}$ & $\%$ & \\
\hline Myocardial infarction & 15 & 33 & 9 & 17 & 0.06 \\
\hline Angina & 9 & 20 & 7 & 13 & 0.42 \\
\hline Stroke & 3 & 7 & 0 & 0 & 0.09 \\
\hline Diabetes & 6 & 13 & 4 & 7 & 0.51 \\
\hline Cancer & 7 & 16 & 2 & 4 & 0.08 \\
\hline Osteoporosis & 7 & 16 & 2 & 4 & 0.08 \\
\hline Fibromyalgia & 3 & 7 & 0 & 0 & 0.09 \\
\hline Chronic pain & 10 & 22 & 0 & 0 & $<0.001$ \\
\hline Rheumatoid arthritis & I & 2 & 0 & 0 & 0.46 \\
\hline Osteoarthritis & 10 & 22 & 4 & 7 & 0.05 \\
\hline Ankylosing spondylitis & 1 & 2 & 0 & 0 & 0.46 \\
\hline Skeletal/muscle diseases & 11 & 24 & 2 & 4 & 0.003 \\
\hline Psychiatric diagnosis & 5 & II & 4 & 7 & 0.73 \\
\hline Gastrointestinal disease & 7 & 16 & 4 & 7 & 0.22 \\
\hline Asthma & 20 & 46 & 14 & 28 & 0.09 \\
\hline
\end{tabular}

Abbreviation: COPD, chronic obstructive pulmonary disease.

\section{Differences in breathlessness between COPD patients who did and did not} have pain

As shown in Figure 1, a significantly higher percentage of patients who had pain endorsed the following breathlessness items: "my cough makes me hurt" ( $P=0.004)$; "my cough makes me tired" ( $P=0.006)$; "my cough or breathing disturbs my sleep" $(P=0.001)$; and "I get exhausted easily" $(P=0.027)$.

\section{Impact of selected variables on pain in COPD patients}

As shown in Table 4, based on the results of the logistic regression analysis, after adjusting for the number of comorbidities $(\mathrm{OR}=0.28 ; P=0.026)$, greater breathlessness measured by the SGRQ symptom score $(\mathrm{OR}=1.03 ; P=0.003)$ was significantly associated with pain, while lung function (OR $=1.03 ; P=0.052)$ was nearly significant. The model fit showed that number of comorbidities, breathlessness and lung function explained 23\% (Nagelkerke R-square) of the variability in pain. The Hosmer and Lemeshow test statistic indicated that goodness of fit to the model was satisfactory.

\section{Discussion}

This study is the first to evaluate for differences in subjective and objective respiratory parameters in COPD patients with or without pain. It is interesting that after adjusting for 


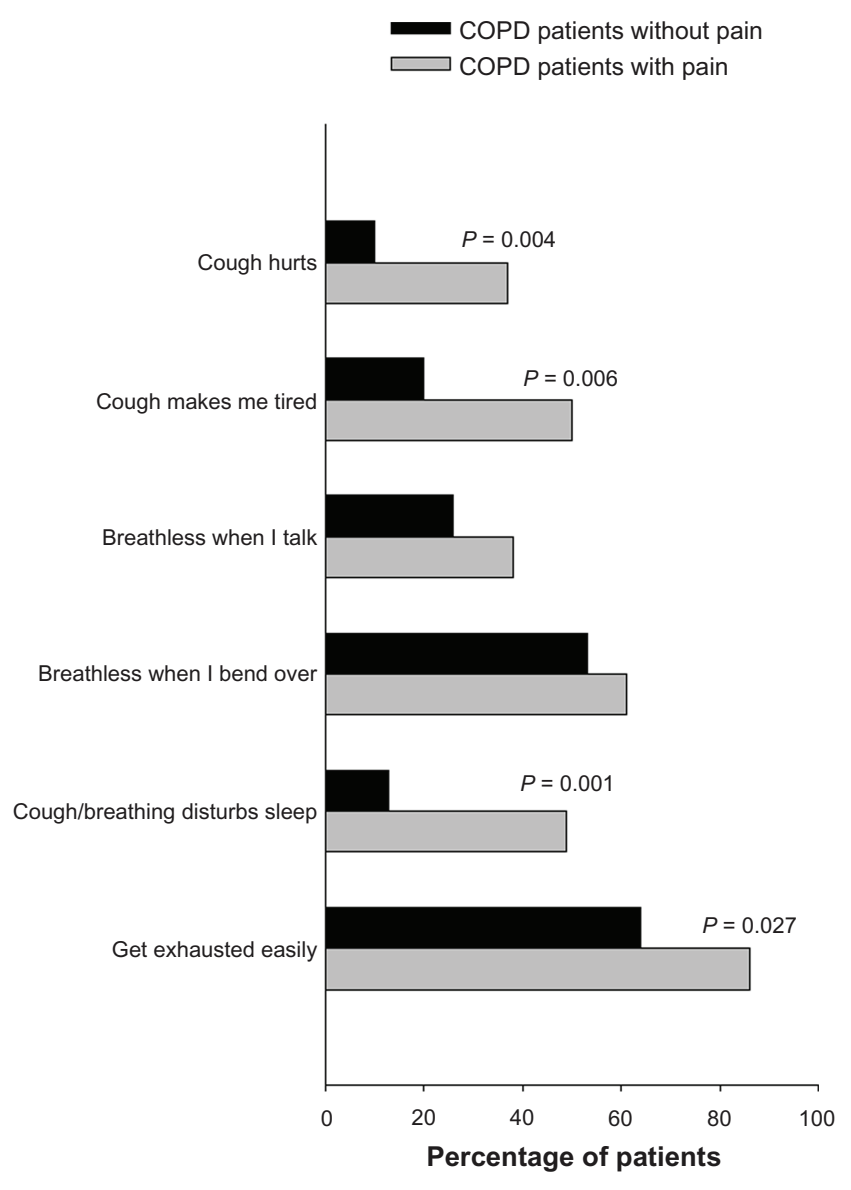

Figure I Differences in the percentages of patients with chronic obstructive pulmonary disease (COPD) who did $(N=45)$ and did not $(N=55)$ have pain who endorsed each of the breathlessness items on the St George's Respiratory Questionnaire.

the number of comorbidities, the COPD patients with pain reported significantly higher breathlessness scores compared to those who did not report pain. In contrast, similar associations were not found for pain and the objective measure of lung function. These findings are consistent with two previous reports that used similar measures. ${ }^{5,6}$ In addition, findings

Table 4 Risk factors of pain in patients with chronic obstructive pulmonary disease assessed by multiple logistic regression analysis $(\mathrm{N}=99)$

\begin{tabular}{lllll}
\hline & B & OR & 95\% Cl & P-values \\
\hline Number of comorbidities & -1.13 & 0.28 & $0.09-0.86$ & $\mathbf{0 . 0 2 6}$ \\
$\begin{array}{l}\text { Breathlessness } \\
\text { (SGRQ, 0-100) }\end{array}$ & 0.03 & 1.03 & $1.01-1.05$ & $\mathbf{0 . 0 0 3}$ \\
$\begin{array}{l}\text { Lung function } \\
\text { (FEV,\% predicted) }\end{array}$ & 0.03 & 1.03 & $1.00-1.06$ & 0.052 \\
\hline
\end{tabular}

Notes: The corresponding logistic regression model fitted to these data using Hosmer and Lemeshow Test. Regression coefficients (B), Adjusted odds ratios (OR) (95\% confidence interval), and $P$-values.

Abbreviations: COPD, chronic obstructive pulmonary disease; FEV expiratory volume in I second; SGRQ, St George's Respiratory Questionnaire. across these quantitative studies are consistent with a recent qualitative study of COPD patients who were interviewed about their pain experiences. Some of these patients described their pain as "tying up the body," which makes it impossible to breathe normally and in turn resulted in increased pain. ${ }^{4}$ A growing body of evidence suggests that these distinctly different sensations share important characteristics. The relationship between pain and breathlessness may be partially explained by the fact that these sensations are mediated within a larger brain network in the anterior insula. Both sensations alert the brain and motivate adaptive behaviors. ${ }^{9}$ Additional research is warranted to examine the commonalities and differences in these two sensations.

In this study, a significantly higher percentage of COPD patients with pain reported that their cough made them hurt, that their cough made them tired, that breathlessness/cough disturbed their sleep, and that they became exhausted easily. These findings are consistent with a study by Williams and colleagues,${ }^{22}$ which found that patients with COPD reported that breathlessness was painful, made them tired and weak, and led to general exhaustion. Again, the association between these respiratory descriptors and pain provide additional evidence that breathlessness and pain may share more than common cortical pathways. ${ }^{9}$ Pain is a complex symptom that is caused by many different bodily changes. ${ }^{23}$ COPD is a complex progressive lung disease. As the disease progresses, elastic tissues in the lung are damaged, which leads to increased mucous hypersecretion, cough, airway narrowing, decreased oxygen saturation, and breathlessness. ${ }^{14}$ These pathophysiologic changes may lead to pain, sleeplessness, fatigue, and exhaustion. ${ }^{4}$ The disease progresses the airflow limitations and decreases in ventilation may increase respiratory muscle work and the work of breathing ${ }^{24,25}$ which in turn may result in fatigue, exhaustion, and pain. ${ }^{4}$ An equally plausible hypothesis is that breathlessness and increased muscle work may lead to muscle hypertonicity and fatigue, which in turn results in increased ventilatory drive associated with greater breathlessness. ${ }^{4,10} \mathrm{~A}$ third hypothesis to explain the associations between cough, breathlessness, and pain in COPD patients is that coughing can lead to pain for mechanical reasons and results in fatigue because it requires energy. ${ }^{4,10}$ All of these hypotheses warrant testing in future studies.

Of note, those COPD patients who had pain reported a significantly higher number of comorbidities than those who did not have pain. In addition, a higher percentage of COPD patients with pain reported the occurrence of chronic pain and musculoskeletal disorders. As is seen in 
patients with other chronic medical conditions, ${ }^{26,27}$ patients with COPD may have pain associated with COPD, pain associated with other chronic medical conditions, and/or pain associated with both their COPD and other chronic medical conditions. Additional research is warranted to determine the specific and/or multiple etiologies for pain in patients with COPD.

A surprising finding was that no differences were found in any demographic characteristics (eg, age, sex, education, marital status, employment status) between COPD patients with and without pain. These findings differ from a previous study of pain in the general Norwegian population, ${ }^{28}$ which found that being younger, being female, having less formal education, living alone, and being unemployed were associated with chronic pain. The reasons for these differences are not readily apparent and warrant investigation in future studies.

Several study limitations need to be acknowledged. Because of the relatively small sample size, additional differences in both subjective and objective respiratory parameters between COPD patients with and without pain warrant investigation in future studies. According to the biopsychosocial model, pain is associated with physiologic as well as psychosocial factors. ${ }^{29-31}$ Therefore, future studies with larger samples may determine additional demographic and sociocultural characteristics associated with pain group membership. Finally, the COPD patients in this study were about to begin a pulmonary rehabilitation program. Therefore, this sample that consisted of patients who had primarily moderate to severe COPD, is not a representative sample of all COPD patients.

Despite the low sample size in this study, breathlessness is associated with pain, which indicates that increased breathlessness may result in pain. By striving for greater understanding of the relationship between breathlessness and pain, the authors suggest that there should be a stronger focus on the relationship between breathlessness and pain when precise and effective COPD interventions are planned.

\section{Conclusion}

In conclusion, the findings from this study suggest that pain is a significant problem in patients with COPD. In addition, COPD patients who had pain reported a higher number of comorbidities and breathlessness than COPD patients who did not have pain. Additional research is warranted to more completely characterize the causes and multiple dimensions of the pain experience of patients with COPD during various stages of their disease and treatment. A stronger focus on the relationship between breathlessness and pain when precise and effective COPD interventions are planned is recommended.

\section{Acknowledgments}

This study was supported by a grant from Haugesund Hospital, Department of Research. Dr Miaskowski is supported by grants from the National Institutes of Health and the American Cancer Society.

\section{Disclosure}

The authors have no conflicts of interest to disclose.

\section{References}

1. Blindermann CD, Homel P, Billings A, Tennstedt S, Portenoy RK. Symptom, distress and quality of life in patients with advanced chronic obstructive pulmonary disease. J Pain Symptom Manage. 2009;38(1): 115-123.

2. Elkington H, White P, Addington-Hall J, Higgs R, Edmonds P. The healthcare needs of chronic obstructive pulmonary disease patients in the last year of life. Palliat Med. 2005;19(6): 485-491.

3. Skilbeck J, Mott L, Page H, Smith D, Hjelmeland-Ahmedzai S, Clark D. Palliative care in chronic obstructive airways disease: a needs assessment. Palliat Med. 1998;12(4):245-254.

4. Lohne V, Heer HCD, Andersen, M, Miaskowski C, Kongerud J, Rustøen T. Qualitative study of pain of patients with chronic obstructive pulmonary disease. Heart Lung. 2010;39(3):225-234.

5. Stavem K, Boe J, Erikssen J. Health status, dyspnea, lung functions and exercise capacity in patients with chronic obstructive pulmonary disease. Int J Tuberc Lung Dis. 1999;3(10):921-926.

6. Borge $\mathrm{CH}$, Wahl AK, Moum T. Association of breathlessness with multiple symptoms in chronic obstructive pulmonary disease. $J A d v$ Nurs. 2010;66(12):2688-2700.

7. Melzack R, Torgerson SW. On the language of pain. Anesthesiology. 1971;34(1):50-59.

8. American Thoracic Society (ATS). Dyspnea. Mechanisms, assessment, and management: a consensus statement. Am J Respir Crit Care Med. 1999;159(1):321-340.

9. Lansing RW, Gracely RH, Banzet RB. The multiple dimensions of dyspnea: review and hypotheses. Respir Physiol Neurobiol. 2009;167(1): 53-60.

10. O`Donell D, Banzett R, Carrieri-Kohlman V, et al. Pathophysiology of dyspnea in chronic obstructive pulmonary disease: a roundtable. Proc Am Thorac Soc. 2007;4(2):145-168.

11. Zautra AJ, Fasman R, Davis MC, Craig AD. The effects of slow breathing on affective responses to pain stimuli: an experimental study. Pain. 2010;149(1):12-18.

12. Quanjer PH, Tammeling JE, Cotes JE, et al. Lung volumes and forced ventilatory flows. Report working party standardization of lung function tests. European community for steel and coal. Official statement of the European respiratory society. Eur Respir J. 1993;16: $5 \mathrm{~S}-40 \mathrm{~S}$.

13. Gulsvik A, Tosteson T, Bakke PS, Humerfelt S, Weiss ST, Speizer FE. Expiratory and inspiratory forced vital capacity and one-second forced volume in asymptomatic never-smokers in Norway. Clin Physiol. 2001; 21(6):648-660. 
14. Committee GS, editor. Global strategy for the diagnosis, management and prevention of chronic obstructive pulmonary disease (GOLD). Global Initiative for Chronic Obstructive Lung Disease [serial on the Internet]. 2010 [cited June 25, 2011]. http://www.goldcopd.org/uploads/ users/files/GOLDReport_April112011.pdf.

15. Bausewein C, Farquhar F, Booth S, Gysels M, Higginson IJ. Measurement of breathlessness in advanced disease: a systematic review. Resp Med. 2007;101(3):399-410.

16. Jones NM, Quirk FH, Baveystock CM. The St George's Respiratory Questionnaire. Respir Med. 1991;85:25S-35S.

17. Jones PW, Quirk FH, Baveystock CM, Littlejohns P. A self-complete measure of health status for chronic airflow limitation. The St George's Respiratory Questionnaire. Am Rev Respir Dis. 1992;145(6):1321-1327.

18. Jones PW, Spencer S, Adie S. The St George's Respiratory Questionnaire Manual. London: Respiratory Medicine, St George's Hospital School; 2003.

19. Barr JT, Schumacher GE, Freeman, S, LeMoine M, Bakst AW, Jones PW. American translation and validation of the St George's Respiratory Questionnaire. Clin Ther. 2000;22(9):1121-1145.

20. Engström CP, Persson LO, Larsson S, Sullivan M. Reliability and validity of the Swedish version of the St George's Respiratory Questionnaire. Eur Respir J. 1998;11(1):61-66.

21. Mölken MR, Roos B, Noord JAV. An empirical comparison of the St George's Respiratory Questionnaire (SGRQ) and the Chronic Respiratory Disease Questionnarire (CRQ) in clinical trial setting. Thorax. 1999;54(11):995-1003.

22. Williams M, Cafarella P, Olds T, Petkov J, Frith P. The language of breathlessness. Differentiates between patients with COPD and agematched adults. Chest. 2008;134(3):489-496.
23. Carrieri-Kohlman V, Lindsey AM, West CM. Pathophysiological Phenomena in Nursing: Human Responses to Illness. Philadelphia: Saunders; 2003.

24. Orozco-Levi M. Structure and function of the respiratory muscles in patients with COPD: impairment or adaptation? Eur Respir J Suppl. 2003;46:41S-51S.

25. MacIntyre NR. Muscle dysfunction associated with chronic obstructive pulmonary disease1. Respir Care. 2006;51(8):840-847.

26. Turk DC, Gatchel RJ. Psychological Approaches to Pain Management. A Practioner's Handbook. 2nd ed. London: Guilford Press; 2002.

27. McMahon SB, Koltzenburg M. Wall and Melzack's Textbook of Pain. 5th ed. London: Elsevier Churchill Livingstone; 2006.

28. Rustøen T, Wahl A, Hanestad BR, Lerdal A, Paul S, Miaskowski C. Prevalence and characteristics of chronic pain in the general Norwegian population. Eur J Pain. 2004;8(6):555-565.

29. Engel GL. The need for a new medical model: a challenge for biomedicine. Science. 1977;196(4286):129-136.

30. Turk DC, Monarch ES. Biosychosocial perspective on chronic pain In: Turk DC, Gatchel RJ, editors. Psychological Approaches to Pain Management: A Practitioner's Handbook. 2nd ed. London: Guildford Press; 2002:3-29.

31. Chapman RC, Nakamura Y, Flores LY. Chronic pain and consciousness: a constructivist perspective. In: Gatchel RJ, Turk DC, editors. Psychosocial Factors in Pain: Critical Perspectives. 1st ed. London: Guilford Press; 1999:35-55.
International Journal of COPD

\section{Publish your work in this journal}

The International Journal of COPD is an international, peer-reviewed journal of therapeutics and pharmacology focusing on concise rapid reporting of clinical studies and reviews in COPD. Special focus is given to the pathophysiological processes underlying the disease, intervention programs, patient focused education, and self management protocols.

\section{Dovepress}

This journal is indexed on PubMed Central, MedLine and CAS. The manuscript management system is completely online and includes a very quick and fair peer-review system, which is all easy to use. Visit http://www.dovepress.com/testimonials.php to read real quotes from published authors. 